Renato Ivče

E-mail: rivce@pfri.hr

Igor Rudan

E-mail: rudan@pfri.hr

Mateo Rudan

E-mail: rudanmateo1@gmail.com

University of Rijeka, Faculty of Maritime Studies, Studentska 2, 51000 Rijeka, Croatia

\title{
Management and Usage of Nitrogen Systems on Liquefied Natural Gas (LNG) Carriers
}

\begin{abstract}
The importance of liquefied natural gas (LNG) vessels and the technology that enables their operations is steadily growing. Hence, in addition to professional interest, the general public also displays a considerably large interest in this issue. Today LNG carriers belong to the category of the most technologically developed vessels and therefore managing these vessels requires not only the general knowledge but also the specific knowledge relating to their cargo handling systems. To ensure the safe and economical transport of LNG by sea and to minimize the risk of fire or explosion it is necessary to understand the properties of LNG and nitrogen, an inert gas used in all phases of the carriage and transfer of liquefied gas.

The subject of this research is the overall process of nitrogen management in daily operations on board LNG carriers. The aim of the research is to explain, evaluate and define the various applications of nitrogen systems on LNG carriers.
\end{abstract}

Key words: LNG carriers, properties of natural gas, properties of nitrogen, cargo handling system, transport of LNG

\section{Introduction}

Liquefied natural gas (LNG) vessels are among the most promising yet most complex technological systems. The contemporary needs of the market are constantly driving innovation in the technological advancement of LNG carriers and their maritime capabilities. The need for this type of vessel had emerged as early as the beginning of the twentieth century and the first vessel for transporting liquefied natural gas was put to sea in the late 1950 s. Today LNG carriers are one of the most technologically 
advanced vessels in international shipping. According to Clarksons Research, the share of LNG vessels was less than $0.05 \%$ in 2017 . There is, however, an exceptionally upward trend in developing and producing LNG newbuildings, as the world natural gas market is opening up and natural gas is increasingly seen, in contemporary studies and by businesses, as one of the cleanest sources of unrenewable energy.

As the importance of LNG vessels and the technology linked to their operation continues to grow, so does the interest of experts engaged in addressing this issue. Hence, this paper focuses on the technology involved in the carriage of LNG by sea.

International regulations concerning liquefied gas carriage have brought important legislations relating to this category of vessels. Especially important are the International Convention for the Safety of Life at Sea (SOLAS), the International Code for the Construction and Equipment of Ships Carrying Liquefied Gases in Bulk (IGC Code) and the International Management Code for the Safe Operation of Ships and for Pollution Prevention (ISM Code). To ensure the safe and economical carriage of liquefied gas by sea and minimize the risk of fire and explosion, it is necessary to understand the characteristics of liquefied gas and nitrogen, an inert gas used in all phases of liquefied gas carriage and transfer. Knowledge of parameters such as pressure, density, temperature and volume is exceptionally important in understanding how ship's systems operate. Focusing primarily on the production, extraction and application of nitrogen as a gas on LNG carriers, the paper attaches the greatest importance to this issue. To address the issue, the paper analyzes all ship's operations (cargo loading, cargo pipeline aeration, reliquefaction system, etc.) involving the use of nitrogen.

\section{International regulations regarding liquefied natural gas carriage by sea}

International regulations for LNG carriage by sea define the minimal safety standards required during exploitation and while a vessel is in port or anchored. Because these regulations have set high standards for LNG carriage by sea, the number of maritime accidents on this type of vessel is very small. The regulations are not static but are open to change, with new regulations, that is, standards, typically being the by-product of a maritime accident. These regulations encompass technical and safety standards for LNG carriage by sea.

Chapter 7 of the SOLAS Convention addresses the carriage of dangerous goods by sea. Part $\mathrm{C}$ of this chapter (Construction and equipment of ships carrying liquefied gases) covers the standards and requirements for vessels carrying liquefied gas by sea and refers to the IGC Code (International Code for the Construction and Equipment of Ships Carrying Liquefied Gases in Bulk) which is applicable to this type of vessel [1].

The IGC Code is an international code prescribing the carriage of liquefied gases by sea. Its purpose is to ensure safe international standards for the construction and equipment of ships carrying liquefied gas by sea and so to reduce any risks to the ship, crew and the environment. The IGC Code is applicable to all vessels used for the carriage of liquefied gas with a saturated gas vapour pressure exceeding 2.8 bar and 
a temperature of $37.8^{\circ} \mathrm{C}$. Chapter 17 of the IGC Code (Special Requirements) refers to the application and purpose of using nitrogen in LNG carriers. The chapter also describes the procedures in nitrogen usage and the conditions and standards a vessel needs to meet with regard to exploitation, maintenance, cargo handling, tank inspection in dry dock, etc. Chapter 5 (Ship's Piping Systems) and Chapter 11 (Fire Protection and Fire Extinction) are concerned with the management and purpose of nitrogen usage on LNG carriers. The International Safety Management Code (ISM) was adopted on 4 November 1993 by the resolution of the International Maritime Organisation (IMO).

The ISM Code provides an international code for safety management to ensure the safe operation of ships and prevent pollution. The aim of the ISM code is to put in place international safety standards with regard to all ship's operations [2]. Every shipping company must have a Safety Management System (SMS), the purpose of which is to unite and improve existing procedures, with the ultimate goal of enhancing the safety of persons, vessels and the environment. The shipping company must also ensure that each ship is manned with trained, qualified and medically fit crew, in compliance with national and international requirements. The company is also required to prepare a programme for the identification, description and response to any extraordinary circumstances on board a ship, and to develop a programme of safety training and drills as preparation in case of emergency situations. The importance that flag states have in applying and enforcing the ISM Code should also be noted because it is the flag state that oversees the implementation of the ISM Code on ships under their respective flag.

\section{Important properties of liquefied natural gas and nitrogen}

Liquefied natural gas (LNG) is a mixture of different carbohydrates in a liquid form. The International Maritime Organization defines liquefied gases carried by sea as liquids with an absolute vapour pressure exceeding 2.8 bar and a temperature of $37.8^{\circ} \mathrm{C}$ [3]. Saturated vapour pressure is considered the most important property of LNG; it is the absolute pressure at which a liquid is in equilibrium with its own vapours at a given temperature. LNG is a colourless, odourless liquid kept at a temperature slightly below the boiling point at a relative pre-pressure of $60 \mathrm{mbar}$ to $100 \mathrm{mbar}$ [4]. Volume is an exceptionally important element in the carriage of LNG because as the temperature of the liquid rises and its density decreases, its volume expands causing pressure to grow on the walls of the cargo tank. One cubic meter of LNG is equal to six cubic meters in a gaseous state and this is the reason why methane is carried by sea in a liquefied state - near boiling point $\left(-161.5^{\circ} \mathrm{C}\right)$ and at atmospheric pressure [5]. Hence, temperature is also extremely important because the cargo is carried at a temperature of $-161.5^{\circ} \mathrm{C}$. An increase in temperature will disrupt the volume of the cargo; the volume of the cargo will grow, leading to an increase in pressure on the surface of the walls of the tank on the vessel. The relative density of LNG is less than 1 (the relative density of LNG at the atmospheric boiling point is $0.427 \mathrm{~kg} / \mathrm{dm}^{3}$ and the relative density of gas vapour 
is $0.554 \mathrm{~kg} / \mathrm{dm}^{3}$ ), meaning that liquefied gases will remain on the surface of the sea in the form of a white layer of fog until they evaporate [3]. In LNG carriage by sea, the reason why the cargo is heated prior to being discharged into the atmosphere (in emergency situations) is to reduce the density of the gas to ensure it does not linger on the ship's deck where there are many potential sources of ignition.

Nitrogen $\left(\mathrm{N}_{2}\right)$ is an inert colourless, odourless and tasteless gas [3]. The share of nitrogen by volume in the atmosphere is $78.08 \%$, making nitrogen the most widelyspread gas in the atmosphere. The capacity of a ship's nitrogen generator is the main factor dictating the amount of nitrogen that can be produced. Accordingly, an LNG carrier is capable of producing nitrogen of a specific quality (composition of inert gases is presented in Table 1). However, as the quality of the produced nitrogen increases, the nitrogen production capacity drops drastically. With regard to chemical properties and reactivity, nitrogen is the only gas that is compatible with all liquefied gases. Nitrogen has a boiling point of $-195.8^{\circ} \mathrm{C}$ [5]. Inert gas cannot be used in daily ship operations because LNG can be contaminated. However, nitrogen is clean and easily dispensable gas. Considering this, the comparison of inert gas and nitrogen is shown in Table 1.

Table 1 - Inert gas comparison

\begin{tabular}{|c|c|c|}
\hline COMPONENTS & INERT GAS BY COMBUSTION & $\begin{array}{c}\text { NITROGEN MEMBRANE } \\
\text { SEPARATING PROCESS }\end{array}$ \\
\hline NITROGEN & $85-89 \%$ & DO $99.5 \%$ \\
\hline CARBON DIOXIDE & $14 \%$ & - \\
\hline CARBON MONOXIDE & $0.1 \%$ & - \\
\hline SULPHUR OXIDES & $0.1 \%$ & - \\
\hline OXIDES OF NITROGEN & IN TRACES & $-65^{\circ} \mathrm{C}$ \\
\hline DEW POINT & $-45^{\circ} \mathrm{C}$ & - \\
\hline ASH AND SOOT & EXIST & $0.9672 \mathrm{~kg} / \mathrm{m} 3$ \\
\hline DENSITY (AIR $=1.00)$ & $1.035 \mathrm{~kg} / \mathrm{m} 3$ & \\
\hline
\end{tabular}

Source: [5]

Table 1 shows that combustion-generated inert gas contains fully $14 \%$ of carbon dioxide. It also contains ash and soot. One of the reasons why this gas is not suitable for use in LNG carriage by sea is that carbon particles (ash and soot) could affect the composition of LNG. Because carbon dioxide freezes at $-55.6{ }^{\circ} \mathrm{C}$, there is also a great threat of operational difficulties, that is, the clogging of pumps, valves and filters. Another significant limiting factor is the humidity of inert gas, because when moist it can condense and form hydrates in cargo tanks or enclosed spaces thus causing corrosion. To avoid this from happening, when loading cargo that has an exceptionally low temperature, it is necessary to keep the dew point at a sufficiently low level to prevent water vapour from freezing. 


\subsection{Nitrogen generation on LNG carriers}

Nitrogen used on LNG carriers can be obtained from resources on shore or from a ship's nitrogen production system. Nitrogen generation on LNG carriers, however, is limited while its procurement in liquid form is impractical and expensive. Instead of nitrogen, the inert gas from exhaust gases in the ship's inert gas system can be used. The operation of a nitrogen generation system on LNG carriers is typically based on the separation of nitrogen from the atmosphere. This type of system is capable of producing nitrogen of $95 \%$ to $97 \%$ purity [5]. The greater the purity of nitrogen required, however, the lower the capacity of the on-board nitrogen generation system. LNG carriers mostly have two nitrogen generators located in the engine room.

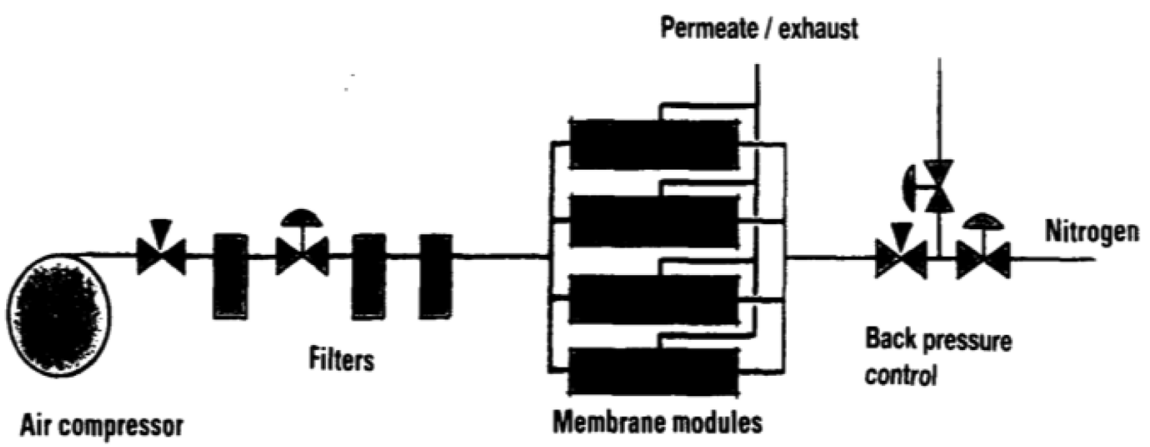

Figure 1 - Schematic view of nitrogen generator Source: [5]

The above figure illustrates part of the nitrogen production system used on LNG carriers and highlights the important elements of nitrogen production systems on such vessels. These are the air compressor, nitrogen generators and buffer tanks. The main limiting factor in obtaining nitrogen from the shore is the capacity of land-based nitrogen production systems. The demand for nitrogen may be so great in certain cases that the crew is forced to seek the procurement of nitrogen from the shore.

Air compressors lead air to the filters and membranes of the nitrogen generator and must ensure the appropriate inlet pressure of the air. Before the air reaches the filters, the air compressors push it towards an electrical heater that raises the temperature of the air from $8{ }^{\circ} \mathrm{C}$ to approximately $50^{\circ} \mathrm{C}$, which is the optimal temperature of air for this type of process. From there, the air continues on to the filters and membranes [6].

A filter and membrane system separates air into component particles as the air passes through hollow fibre membranes. The following figure presents a diagram illustrating the principle of nitrogen separation from air: the membranes separate air into two streams, one containing nitrogen and the other, oxygen, carbon dioxide and other 
gases. The stream containing oxygen, carbon dioxide and other gases is discharged into the atmosphere, while the stream containing nitrogen continues on to the buffer tanks.

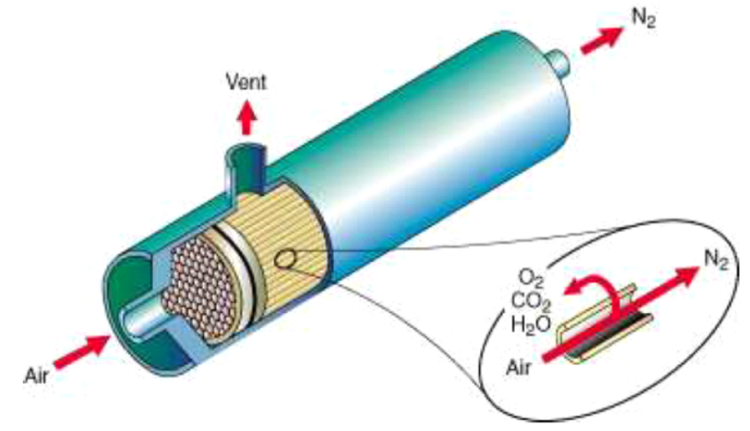

Figure 2 - Separating nitrogen through the membrane Source: [5]

For a better understanding of how the system operates, it is essential to explain certain properties of air. Namely, air is separated in the membranes because of its permeability rate. It also possesses the properties of neutralization through membranes and dissolution. Because nitrogen has a lower flow rate than oxygen, water, carbon dioxide and other gases through the membrane, it is separated from the overall composition of air. If, for some reason, traces of oxygen, carbon dioxide and/or other gases should appear in the "pure" nitrogen, the system's built-in sensors that constantly monitor the quality and purity of nitrogen will activate an alarm and the production of nitrogen will be stopped.

A nitrogen generator has a capacity of up to $15,000 \mathrm{~m}^{3} / \mathrm{hour}$ [3]. Its capacity largely depends on the type of cargo system on board, the size of the vessel and on whether there is an on-board system for the reliquefaction of evaporated natural gas. According to the authors Vorkapić, Kralj, Bernečić [6] evaporation of natural gas is inevitable due to difference in temperature between cargo and the ambiance i.e., air and sea. Accordingly, the rate of nitrogen usage for the regasification will be proportional to the rate of boiled gas. Procurement of nitrogen from shore is typically carried out after docking when the need for nitrogen is exceptionally great and the capacities of on-board nitrogen generators are not capable of meeting the demand for nitrogen. During docking it is necessary to initially fill the entire system with nitrogen, that is, the intermembrane spaces on membrane-type vessels, the sealing part of the cargo compressor barrier with electric motor in the compressor room, as well as the reliquefaction system, if the vessel has one. In the initial filling the largest amount of nitrogen is used to fill hold spaces and interbarrier spaces of tanks. According to authors Vanem et. al. [7] it is noted that membrane tanks have experienced cargo tanks leakage through its primary barrier, and are also believed to be more vulnerable to effects of dynamic loads and sloshing of LNG cargo. 
By increasing the capacity of buffer tanks, the speed of manipulation of the cargo would also increase. Larger buffer tanks or additional buffer tanks could be located even on the deck resulting in faster cargo handling. During ballast voyages, nitrogen generators could fill the additional buffer tanks resulting in faster cargo operations in port.

\subsection{Use of nitrogen on LNG carriers}

As stated earlier, nitrogen is the main limiting factor during ship's operations. To better understand the daily exploitation of LNG carriers, it is important to understand the broad spectrum of nitrogen usage. Nitrogen is used for filling intermembrane spaces, aerating cargo pipelines and vent mast pipelines, preventing corrosion, extinguishing possible fires on vent mast pipelines, preventing the formation of combustible mixtures in intermembrane and insulating spaces, filling the sealing part of the cargo compressor barrier with electric motor in the compressor room, and in reliquefaction.

The use of nitrogen on vessels depends primarily on the type of tanks and the type of systems used for handling cargo. Accordingly, it is important to know the various types of tanks, and their characteristics, used in LNG carriage by sea, considering that the design of a tank has a direct effect on the quantity and application of nitrogen on such vessels. Tanks used in LNG carriage can be divided into independent type "B" tanks and membrane tanks [4].

The filling of intermembrane spaces is particularly important in LNG carriage by sea because of the necessity to maintain constant pressure between primary and secondary membranes. To better understand this issue, this parts of the cargo system needs to be explained. The cargo system refers to the overall cargo containment system that consists of [5]:

- primary barrier (cargo tank),

- secondary barrier (if required, in compliance with the IGC Code),

- associated thermal insulation, isolating spaces (e.g. cofferdams)

- the additional structure needed to support these elements.

The Gaz Transport system maintains a constant level of pressure of nitrogen in intermembrane spaces (between primary and secondary barriers, in the first layer of insulation). The aim of filling the interbarrier spaces with nitrogen is to prevent, and make it easier to detect, the accumulation and freezing of moisture, the rupture of primary membranes (using a detection system), the formation of a combustible mixture resulting from the rupture of a primary membrane, and corrosion [5].

As a gas, nitrogen does not support combustion, which makes it exceptionally compatible for filling the intermembrane space because it will not create a combustible compound in case of leaking through the primary membrane, that is, if LNG should penetrate into the intermembrane space. 
During loading, the overall economic efficiency of the vessel in this operation depends on the capacity of the nitrogen generator because the availability of nitrogen determines the cool-down rate. The larger the capacity of the generator, the faster the rate of cargo tank and cargo pipeline cool-down. Cargo tank cool-down typically takes place during port entry when it is impossible for a vessel to procure nitrogen from shore.

Once cargo handling procedures have been carried out, it is necessary to aerate the cargo pipeline and vent mast pipeline using nitrogen. Pipeline and vent mast aeration is carried out regardless of the size or type of LNG carrier. This procedure is used to remove any remaining LNG without contaminating the cargo.

Some LNG carriers are capable of using LNG boil-off as a fuel, while other vessels have a built-in cargo boil-off reliquefaction system. Maximum boil-off limits have been set for every type of tank. Boil-off commences at the boiling point of LNG.

In the main heat exchanger, the boil-off circulates through tubes that are surrounded by cooled nitrogen. In this process, nitrogen is used as a cooling agent. By passing through the tubes of the main heat exchanger, the boil-off is cooled until it again reaches a temperature of $-161.5^{\circ} \mathrm{C}$ at which it is reliquefied [3]. Once the cargo boil-off has been reliquefied, it continues through piping back to the tank. Nitrogen plays a crucial role in this ship operation because it liquefies at a temperature of $-195.8^{\circ} \mathrm{C}$, which makes it compatible in carrying out this function.

Authors have submitted an inquiry to one of the leading LNG shipping companies seeking to get a "near miss" situation regarding the usage of nitrogen on an LNG vessel. In the history of the company, no "near miss" situation regarding the usage of nitrogen on an LNG vessel has ever happened.

\section{Conclusion}

As modern economies have become aware of the need for natural gases in business operations, maritime activities have increasingly begun adjusting to the new needs of industries. Research works regarding the construction of vessels for carrying LNG by sea began in the early twentieth century, to result in the first LNG carriers in the 1960s. Modern vessels of this type are exceptionally complex in terms of technology and all ship's operations are carried out under strict supervision.

Safe handling of such cargo must be based on its physical principles and their relationships (temperature, pressure, volume, density, etc.) to ensure safe and sustainable voyages, and vessels carrying this cargo are required to implement a series of conventions, codes and national regulations. In vessels carrying LNG by sea it is of utmost importance to prevent cargo contamination, and nitrogen is the only gas that is fully compatible for use in LNG carriage by sea. Nitrogen is used in different ship's operations: in filling intermembrane spaces, aerating cargo pipelines and vent mast pipelines, preventing corrosion, extinguishing possible fires on vent mast pipelines, preventing the formation of combustible mixtures in intermembrane and insulating 
spaces, filling the sealing part of the cargo compressor barrier with electric motor in the compressor room, and in reliquefaction.

The speed of cargo handling in port will increase by placing more nitrogen buffer tanks on board. Nitrogen as a gas is not flammable and does not represent a risk regarding safety and environment protection. Accordingly, additional nitrogen buffer tanks could be placed even on a deck resulting in greater availability for cargo manipulations.

In optimizing the business side of LNG carriers, the optimal use of nitrogen is a crucial factor in the overall process of cargo carriage by sea because the capacity and availability of nitrogen on LNG carriers dictates the speed at which a large number of ship's operations are carried out. However, this paper is a base for future researches related to faster and safer exploitation of LNG vessels.

\section{References}

1. Zec, D. (2001) Sigurnost na moru. Rijeka, Pomorski fakultet.

2. ISM Code, 3. edition (2010) London, IMO.

3. Bronzan, B. (1999) LNG. Zagreb, Energetika marketing.

4. Komadina P., et al. (1992) Prijevoz ukapljenih plinova morem. 2. izdanje, Rijeka, Pomorski fakultet Sveučilišta u Rijeci.

5. McGuire, W. (1996) Liquefied gas handling priciples: on ships and in terminals. sec. ed. London, Witherby \& Company Limited.

6. Vorkapić, A., Kralj, P., Bernečić, D. (2016) Ship systems for natural gas liquefaction, Scientific journal of martime research, 30, 105-112. Available from: https://www.pfri.uniri.hr/web/en/ documents/pomorstvo/2016/12/371-Vorkapic-Kralj-Bernecic.pdf [Accessed 20th October 2018].

7. Vanem, E., Antao, P., Ostvik, I., Del Castillo de Comas, F. (2008) Analysing the risk of LNG carrier operations, Reliability Engineering and System Safety, 93, 1328-1344. Available from: https:// www.researchgate.net/publication/223190585_Analysing_the_risk_of_LNG_carrier_operations [Accessed 15th October 2018]. 
